\title{
Influences of Hot-Isostatic-Pressing Temperature on the Microstructure, Tensile Properties and Tensile Fracture Mode of $2 A 12$ Powder Compact
}

\author{
Gang Wang ${ }^{1} \cdot$ Li-Hui Lang ${ }^{1} \cdot$ Wen-Jun $\mathrm{Yu}^{2} \cdot \mathrm{Xi}-\mathrm{Na} \mathrm{Huang}^{1} \cdot \mathrm{Fei}_{\mathrm{Li}^{2}}$
}

Received: 2 April 2016/Revised: 4 June 2016/Published online: 1 September 2016

(C) The Chinese Society for Metals and Springer-Verlag Berlin Heidelberg 2016

\begin{abstract}
A12 aluminum alloy powders were hot-isostatic-pressed (HIPed) at representative temperatures for investigating the variation in microstructure, tensile property and fracture mode of the powder compact. It was found that the microstructure of raw powders changed from a dendrite structure to an equiaxed structure from room temperature to $600{ }^{\circ} \mathrm{C}$. The liquid phase produced by the eutectic reaction in the powder was gradually increased and finally formed a liquid pathway that ran through the entire powder from 490 to $600{ }^{\circ} \mathrm{C}$. Prior particle boundaries were observed in the powder compacts HIPed at 490 and $520{ }^{\circ} \mathrm{C}$. The liquid phase in the powder compacts was squeezed into the powder boundaries and the triple points of powder when HIPed at $580{ }^{\circ} \mathrm{C}$. However, the liquid phase located at the triple points of the powder was forced out and moved toward a small powder particle by HIP pressure under an HIPing temperature of $600{ }^{\circ} \mathrm{C}$, which led to a decrease in the mechanical properties and relative density. Better comprehensive properties were obtained at HIPing temperatures of 490 and $580{ }^{\circ} \mathrm{C}$. The low ductility exhibited by the P/M aluminum alloy HIPed at different temperatures was believed to arise from a combination of the existence of oxide film on the powder particle surface and the distribution characteristics of the liquid phase. Finally, three typical types of de-cohesion were classified.
\end{abstract}

KEY WORDS: Powder metallurgy; Hot-isostatic-pressing; Microstructural evolution; Fracture mode; Aluminum alloy; Mechanical properties

\section{Introduction}

Aluminum and its alloys exhibits attractive properties including lightweight, high specific strength, high thermal conductivity and good corrosion resistance $[1,2]$. Recent studies $[3,4]$ show that using aluminum alloy instead of the steel can result in up to $300 \mathrm{~kg}$ mass reduction in a

Available online at http://link.springer.com/journal/40195.

Gang Wang

wanggang198733673@126.com

1 School of Mechanical Engineering and Automation, Beihang University, Beijing 100191, China

2 Avic Chengdu Aircraft Industrial (Group) Co. Ltd, Chengdu 610000, China medium-size vehicle $(1400 \mathrm{~kg})$, and every $100 \mathrm{~kg}$ reduction in weight can yield a cut of $0.3-0.6 \mathrm{~L}$ per $100 \mathrm{~km}$ in fuel consumption and 20\% lower exhaust gas emissions. Aluminum alloy is one of the most promising lightweight materials for the next generation of vehicles [5].

Powder metallurgy $(\mathrm{P} / \mathrm{M})$ is an important processing method for making high strength and rigid aluminum alloys, and $\mathrm{P} / \mathrm{M}$ aluminum alloy is a very promising candidate for various industrial materials in the aerospace and automotive industries, and so on [6]. Conventional pressing and sintering routes have been gaining attention in the automotive industry due to their low costs. $\mathrm{P} / \mathrm{M}$ aluminum alloy is usually fabricated from elemental or pre-alloyed powders through the liquid phase sintering (LPS) technique [7, 8], which has become widely accepted due to the improved mechanical properties [9]. Over the last decade, many researchers have conducted extensive investigations 
into the effect of various sintering conditions on densification, microstructural development and the mechanical properties of the binary $2 \mathrm{xxx}$ series aluminum alloy. Liu et al. [10] found that, compared to spherical powder particles, irregularly shaped powder particles could acquire higher sintered density. Boland et al. [11] showed that the tensile strength of $248 \mathrm{Mpa}$ and yield strength of $186 \mathrm{MPa}$ could be obtained after 2324 aluminum alloy powders were cold-compacted under $400 \mathrm{MPa}$ and then sintered at $600{ }^{\circ} \mathrm{C}$ for $20 \mathrm{~min}$. Schaffer et al. [12] analyzed the relationship between the mechanical properties and the sintering atmosphere of $\mathrm{Al}-\mathrm{Cu}-\mathrm{Mg}(-\mathrm{Si})$ alloy powder and pointed out that the best sintering atmospheres were in order of nitrogen, vacuum and argon. Gokce et al. [13] studied the microstructural and mechanical properties of $\mathrm{Al}-\mathrm{Cu}-\mathrm{Mg}$ powder compacts which were pressed at 400 Mpa and then sintered in a nitrogen atmosphere at $590{ }^{\circ} \mathrm{C}$ for $1.5 \mathrm{~h}$ and found that the transverse rupture strength increased from $86 \mathrm{Mpa}$ to $466 \mathrm{Mpa}$ and the hardness was doubled after sintering. Padmavathi et al. [14] reported the sintering characteristics of the 2712 aluminum alloy in variation with compaction pressure, sintering time and temperature and found that the optimal process parameters for 2712 aluminum alloy powder were $400 \mathrm{Mpa}$ and $590{ }^{\circ} \mathrm{C}$. Besides compaction pressure and sintering temperature, heat treatment also had a significant effect on mechanical properties. However, the conventional pressand-sinter route is not a near-net-shape process for complex aluminum alloy parts and they must undergo subsequent machining. In addition, the resin binder added in the powder compact must be able to be cleanly removed from the compact without leaving any residue, and therefore, a thermal de-binding procedure is needed [15], which necessitates cumbersome processing.

Metal powder (near) net-shape hot-isostatic-pressing (HIPing) can produce components with complex shapes and high material use ratios and improve microstructure uniformity [16]. It combines pressing and sintering in one step and avoids the impurity pollution problems caused by adding binder. Simultaneously, one-step integral fabrication of complex aluminum alloy parts can be achieved with the aid of external restrictions and internal cores. However, most studies focus mainly on the post-treatment of aluminum castings for application of HIPing in aluminum alloy. Staley Jr et al. [17] showed that the HIP process could increase the average and maximum fatigue life of A206-T71 aluminum castings, but increasing HIP temperature had essentially no effect on the casting's threshold fatigue life. Ceschini et al. [18] also found that for the sandcast A356-T6 and A204-T6 aluminum alloys, the HIP process significantly reduced the solidification defects and led to a reduction in fatigue data scattering and an increase in fatigue resistance, which were about $40 \%$ for A356 and
$70 \%$ for A204. Ran et al. [19] demonstrated that the HIP process significantly reduced porosity volume fraction and pore sizes in A356-T6 cast aluminum alloy, and therefore, ductility was improved, but tensile strength was improved only very marginally. The reason for this was ascribed to the brittle nature of the unmodified coarse microstructure after HIP. Islam and Farhat [20] showed that HIP treatment decreased the total amount of porosity and average pore size in cast Al-Si alloy, but at the expense of reduced hardness. The reason for this, they suggest, was the grain growth of the Al matrix caused by the high temperature under the HIP process. However, there have been few studies on the direct preparation of the P/M aluminum alloy using HIPing. In this paper, the 2A12 P/M aluminum alloy was prepared directly using HIPing at different temperatures. The microstructural evolution, mechanical properties and fracture mode of the $\mathrm{P} / \mathrm{M}$ aluminum alloy were investigated. In addition, there is a preliminary exploration of the effect of different temperatures on the microstructure and mechanical properties of the $\mathrm{P} / \mathrm{M}$ aluminum alloy, providing a fundamental base for further research.

\section{Experimental Design}

\subsection{Raw Materials}

The material used in this study was 2A12 aluminum alloy powder (BaoJi Haibao Special Metal Materials Company, China), prepared by the plasma rotating electrode process (PREP). The chemical composition of the $2 \mathrm{~A} 12$ powders is listed in Table 1.

To confirm the partial re-melting temperature, the powder was analyzed by a NETZSCH STA449C integrated thermal analyzer. The result is shown in Fig. 1, and the solidification range is $502-638^{\circ} \mathrm{C}$.

\subsection{HIP Process}

The HIP temperatures were 490, 520, 580 and $600{ }^{\circ} \mathrm{C}$, respectively. The first temperature was below the solidification range, and there should be no liquid phase produced in the powder; the second was between the temperatures of ternary eutectic reaction and binary eutectic reaction; the third was above the temperature of binary eutectic reaction; and the last was near the melting point. In order to observe

Table 1 Chemical composition of 2A12 aluminum alloy powder (wt\%)

\begin{tabular}{llllllll}
\hline $\mathrm{Si}$ & $\mathrm{Fe}$ & $\mathrm{Cu}$ & $\mathrm{Mn}$ & $\mathrm{Mg}$ & $\mathrm{Zn}$ & $\mathrm{Ti}$ & $\mathrm{Al}$ \\
\hline 0.50 & 0.50 & $3.8-4.9$ & $0.30-0.9$ & $1.2-1.8$ & 0.3 & 0.15 & Bal. \\
\hline
\end{tabular}




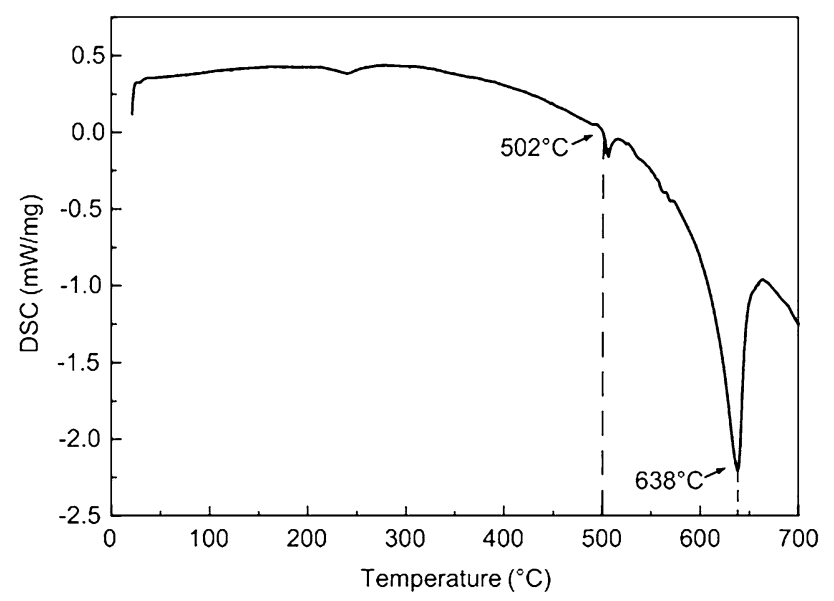

Fig. 1 DSC curve of the 2A12 alloy powder

the microstructural change of raw powder at the four temperatures, the powders were heated for $15 \mathrm{~min}$ at 490 , 520,580 and $600{ }^{\circ} \mathrm{C}$ and then quenched from the designed temperature by dropping them through an aluminum foil seal into a water bath to retain the original structure characteristics of the powders.

The HIP test was carried out on the QIH-15 mini-hipper made in ABB. The powder was poured into a pure aluminum capsule, which was degassed and vacuum sealed, and then HIPed. The degassing process consisted of three steps: the first step was conducted at room temperature for $4 \mathrm{~h}$, the second at $150{ }^{\circ} \mathrm{C}$ for $2 \mathrm{~h}$ and the third at $400{ }^{\circ} \mathrm{C}$ for $6 \mathrm{~h}$. All the powder capsules were held at the HIP temperature for $3 \mathrm{~h}$ under pressure of $130 \mathrm{Mpa}$ and then were cooled in the furnace to room temperature. The argon gas used for HIPing was kept in the furnace during the cooling process. The HIP temperatures were 490, 520, 580 and $600{ }^{\circ} \mathrm{C}$, respectively. Detailed conditions of the HIP and the specimens after HIP are shown in Figs. 2 and 3. To

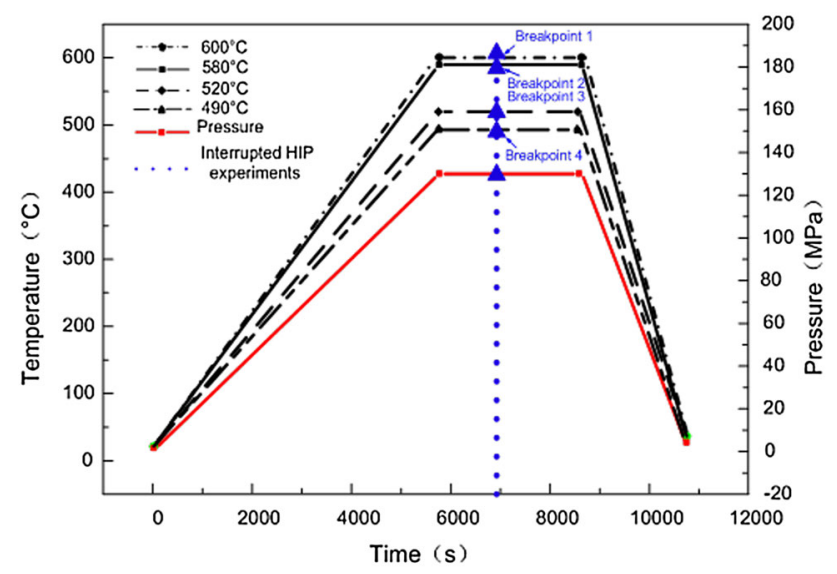

Fig. 2 Technology curve of HIP

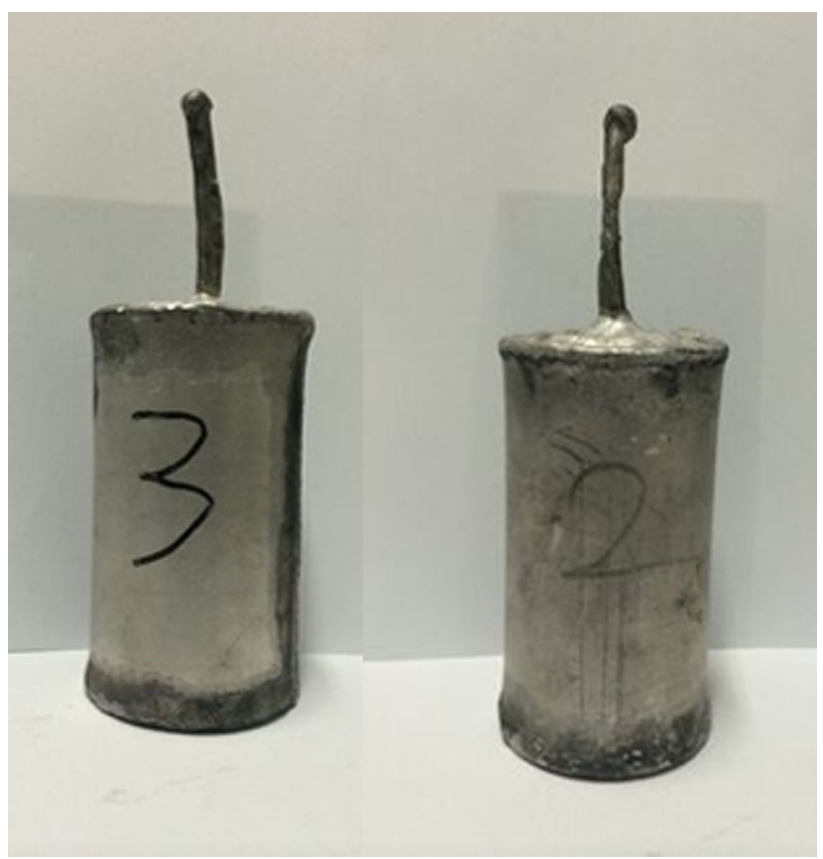

Fig. 3 Specimens after HIP

further investigate the microstructural evolution of the powder compacts at different temperatures, interrupted HIP experiments were conducted after temperature preservation/pressure holding for $15 \mathrm{~min}$, as shown by the blue dashed line in Fig. 2.

\subsection{Characterization}

The size distribution of the powder was determined by a Mastersizer 2000 laser size analyzer. The density of the powder compact was evaluated using Archimedes' principle. For microscopic observations, the powders and the samples after HIPing were mounted in an epoxy resin, polished and then etched with Keller's etchant (HF:HCI: $\mathrm{HNO}_{3}: \mathrm{H}_{2} \mathrm{O}=1: 1.5: 2.5: 95$ ) for $40 \mathrm{~s}$. The OLYMPUSB $\times 51 \mathrm{M}$ metallographic microscopy (OM), CS3400 scanning electron microscopy (SEM) and JXA8100 electron probe micro-analyzer (JPMA) were used to observe the microstructure evolution of the raw powder and the powder compact HIPed under different HIPing temperatures. The phase composition of the powders was characterized by X-ray diffractometer (D/MAX-2500) using high-energy monochromatic radiation in the $2 \theta$ range from $10^{\circ}$ to $100^{\circ}$ at a scan rate of $2 \% \mathrm{~min}$. The tensile tests were carried out on an electronic universal testing machine(QJ210), based on GB/T 228-2002 Metallic material-Tensile testing at ambient temperature, and the tensile fracture surfaces were examined using SEM. 


\section{Results and Discussion}

\subsection{Characterization of the Rapid Solidified Powders}

Figure 4 shows the morphology, size distribution and cross-sectional microstructure of the aluminum alloy powders. It can be seen that most powders have a perfect round morphology and uneven distribution in all the size ranges; about $90 \%$ of powders are in the $150-200 \mu \mathrm{m}$ (Fig. 4b). The coarse powders have satellites, as indicated by the red arrow in Fig. 4a. This phenomenon was also found in other research reports [21]. Wang et al. [22] believed the reason for this may be that the small powder particles have large surface tension and undercooling compared with the large powder particles and they could solidify preferentially. In this case, the small solidified powders would collide with unsolidified large droplets and cold weld together, finally forming the small satellite-like sphere. The as-received powder particles generally show a dendritic surface and there are no precipitates on the surface (see the enlarged inset in Fig. 4a). The dendritic microstructure could also be observed on the section of the particle, see the enlarged figure in Fig. 4c. The inter-dendritic regions of the as-received powder usually appeared bright due to atomic number contrast in the backscattered electron SEM image, which suggested the presence of a higher concentration of higher atomic number elements. This was further verified by EDS analysis in the interdendritic and matrix areas (Fig. 4d). From Fig. 4d, several elements, such as $\mathrm{Cu}$ and $\mathrm{Mg}$, were detected by EDS at point 1 , suggesting that it may be the mixture of $\alpha(\mathrm{Al})$ and binary phase/ternary phase $\mathrm{Al}-\mathrm{Cu}-\mathrm{Mg}$. Figure 5 demonstrates the XRD analysis of the powders, showing that the phase composition in the powders contained $\alpha(\mathrm{Al})$ phase, $\theta\left(\mathrm{CuAl}_{2}\right)$ phase, $S\left(\mathrm{Al}_{2} \mathrm{CuMg}\right)$ phase and $\mathrm{MgAl}_{2} \mathrm{O}_{4}$ at different temperatures. $\mathrm{Al}_{2} \mathrm{O}_{3}$ phase was detected when the temperature reached $600{ }^{\circ} \mathrm{C}$ due to the oxidation of aluminum alloy powders during the heating process. The presence of the $\mathrm{Al}_{2} \mathrm{O}_{3}$ phase was also examined by $\mathrm{Yu}$ et al. [23] at room temperature, and they suggested that the formation of oxide film was the result of contact between the powder and air in the process of transportation and degassing. Li et al. [24] studied the microstructural
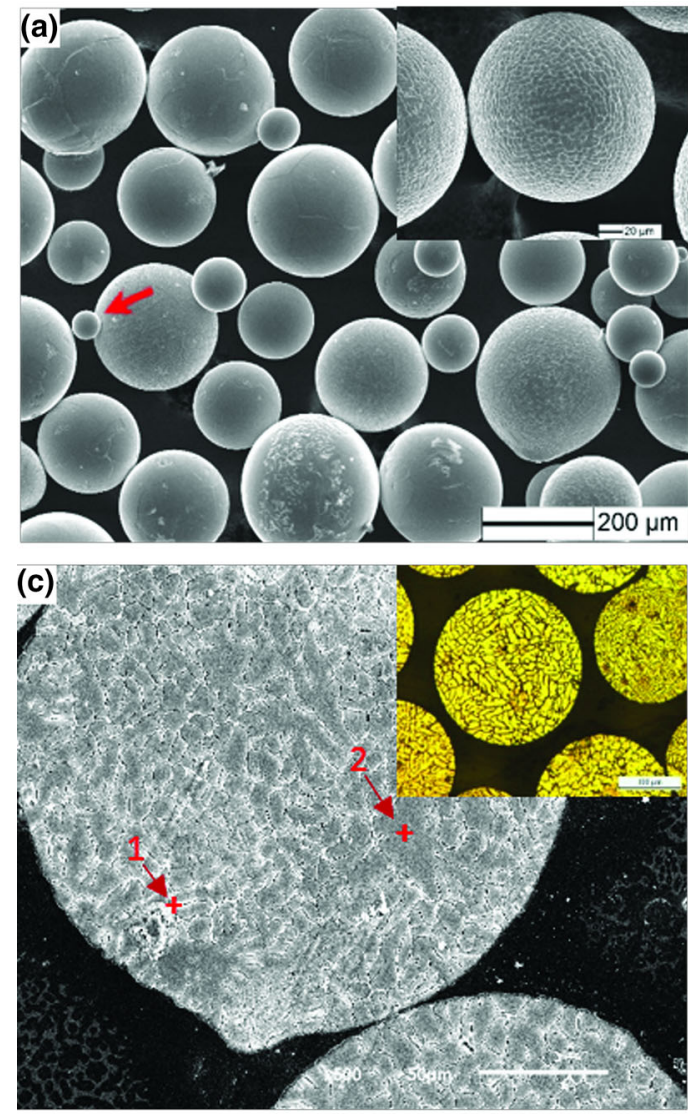

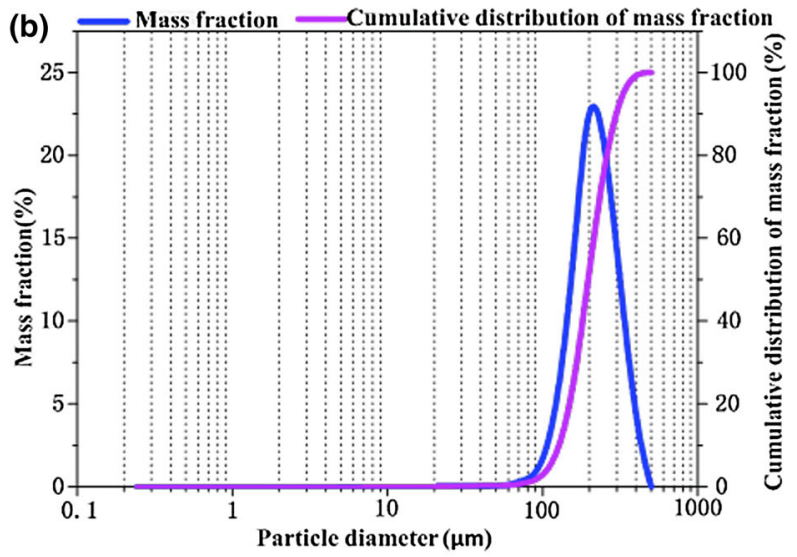

(d)
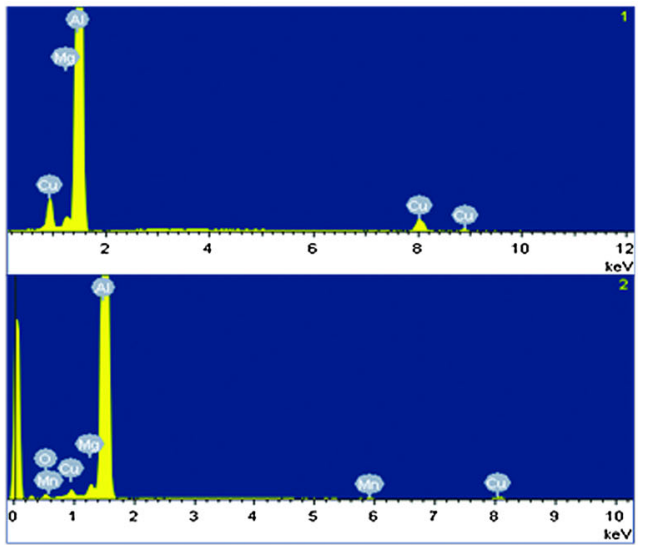

Fig. 4 Morphology a, size distribution $\mathbf{b}$ and cross-sectional microstructure $\mathbf{c}$ of the rapidly solidified powder, EDS spectra of the precipitates marked 1 and 2 in $\mathbf{c}, \mathbf{d}$ 


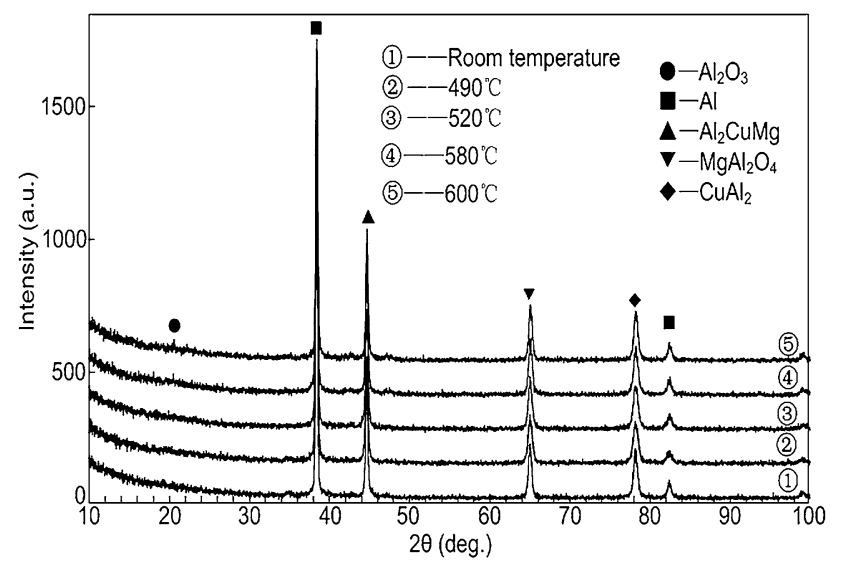

Fig. 5 XRD spectra of $2 \mathrm{~A} 12$ powders

evolution of 2024 aluminum alloy powders during the heating process and found that the phase located at the inter-dendritic regions mainly contained $\theta$ phase and $\alpha$-Al phase; $S$ phases were not detected because of its low content. A possible explanation for the dendritic segregation is that the cooling velocity of the powders achieves $10^{4}{ }^{\circ} \mathrm{C} / \mathrm{s}$ [25] during the PREP process, so there is not enough time for alloy elements to diffuse into Al matrix, and most alloy elements remained in the inter-dendritic regions.
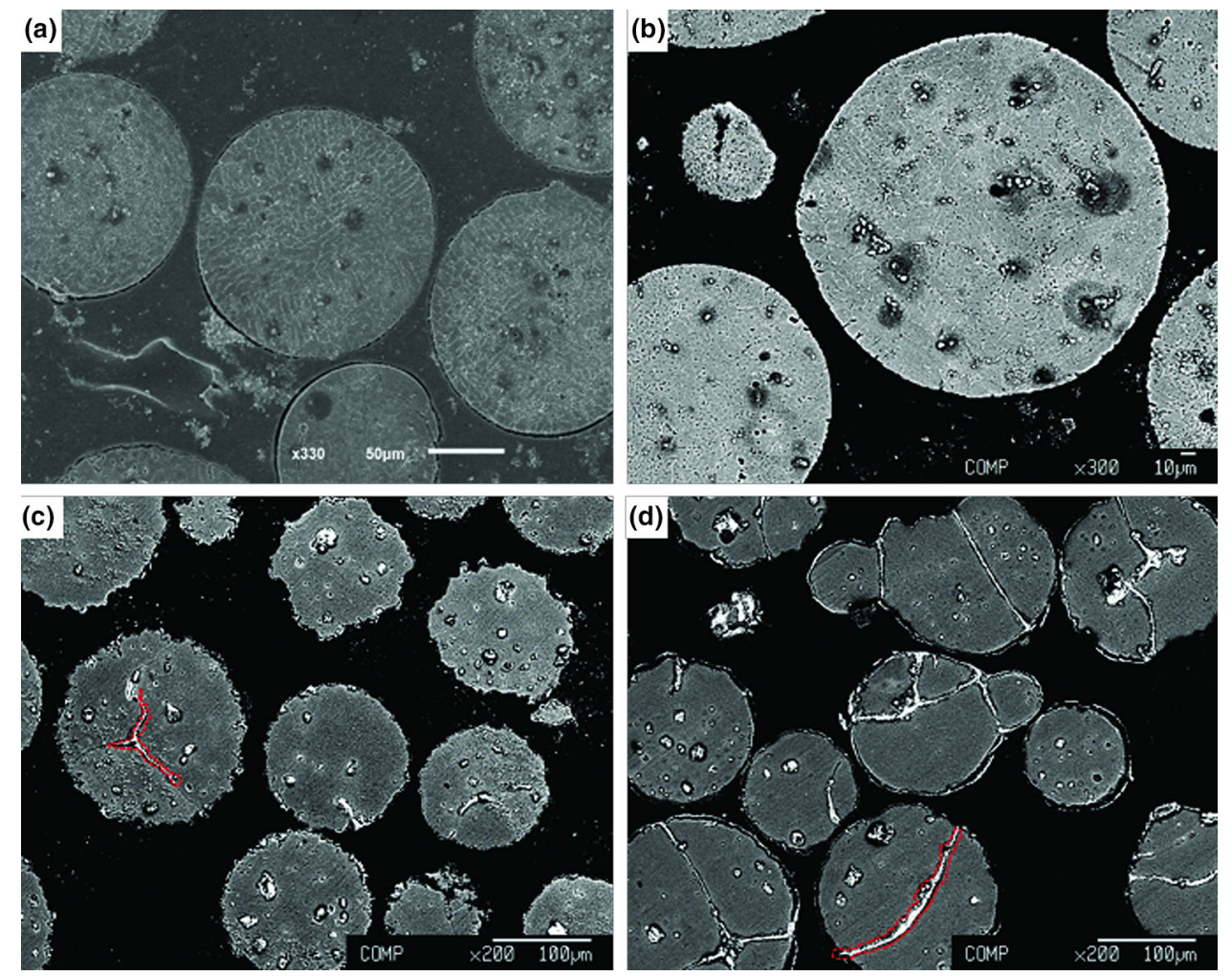

Fig. 6 Microstructures of $2 \mathrm{~A} 12$ powders isothermally held for $15 \mathrm{~min}$ at different temperatures: a $490{ }^{\circ} \mathrm{C}$; b $520{ }^{\circ} \mathrm{C}$; c $580{ }^{\circ} \mathrm{C}$; d $600{ }^{\circ} \mathrm{C}$ 


$$
L \rightleftarrows \alpha(\mathrm{Al})+\theta\left(\mathrm{CuAl}_{2}\right)+S\left(\mathrm{Al}_{2} \mathrm{CuMg}\right) .
$$

With the rise of the temperature (to $550{ }^{\circ} \mathrm{C}$ ), the amount of liquid phase was further increased due to the occurrence of the binary eutectic reaction.

$L \rightleftarrows \alpha(\mathrm{Al})+\theta\left(\mathrm{CuAl}_{2}\right)$.

However, because the $S$ phase within powder particles is very small, it is believed that the content of the liquid phase produced by the ternary eutectic reaction was small. Mi and Grant [27] adopted the Scheil equation to relate the alloy liquid fraction and the temperature during the heating process.

$f_{1}=\left(\frac{T-T_{\mathrm{s}}}{T_{1}-T_{\mathrm{s}}}\right)^{(1 /(1-K))}$

where $f_{1}$ is liquid fraction, $T_{\mathrm{s}}$ and $T_{1}$ are the solidus and liquidus temperature of the alloy, respectively, and $k$ is a partition coefficient. Figure 7 shows the liquid fraction of 2A12 aluminum alloy as a function of temperature; actually, it is fit to the data calculated by MATLAB using Eq. (1) with $k=0.66$ and the corresponding liquid fraction is summarized in Table 2.

As shown in Fig. 7 and Table 2, the liquid fraction increases with an increase in temperature. When the temperature reached 580 and $600{ }^{\circ} \mathrm{C}$, the liquid fraction reached 20.23 and $38.14 \%$, respectively. A large number of liquid phases produced within $\mathrm{Al}$ powders aggregate to form a liquid pathway; however, it is noteworthy that the liquid phase did not form a continuous pathway that ran through the entire powder until the temperature reached $600{ }^{\circ} \mathrm{C}$ (see the red dashed line in Fig. $6 \mathrm{c}$, d). Further, from Fig. $6 c$, it can be seen that the edges of the powder show a jagged morphology at $580{ }^{\circ} \mathrm{C}$, but at $600{ }^{\circ} \mathrm{C}$ the edges of the powder become round and smooth. The reason for this

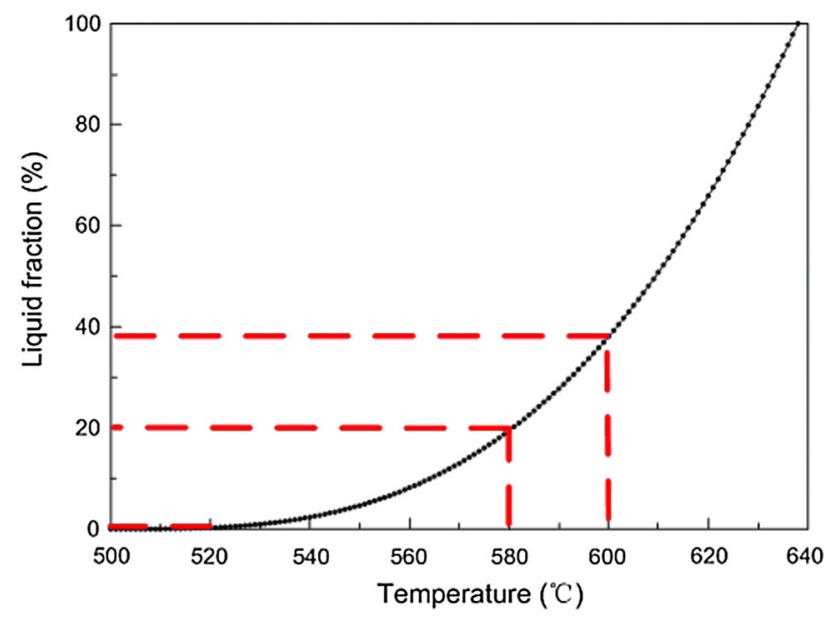

Fig. 7 Effect of the temperature on liquid phase fraction of 2A12 aluminum alloy powders
Table 2 Liquid fraction at different temperatures

\begin{tabular}{lllll}
\hline Temperature $\left({ }^{\circ} \mathrm{C}\right)$ & 490 & 520 & 580 & 600 \\
\hline Liquid fraction $(\%)$ & 0 & 0.26 & 20.23 & 38.14 \\
\hline
\end{tabular}

might be that the liquid phase was initially generated at the joints between the matrix and precipitated phase [28], and the cohesion force between them became weak. The precipitated phase located at the edge of the powder might be direct de-cohesion from the matrix in the cooling process, which might be the cause of the edge of the powder showing a jagged morphology at $580{ }^{\circ} \mathrm{C}$. But this phenomenon did not occur in the process of HIP due to the existence of HIPing pressure. However, the liquid phase had formed a continuous pathway that ran through the entire powder at $600{ }^{\circ} \mathrm{C}$. Excess liquid phase overflowed from the liquid pathway, and a continuous liquid layer was formed to cover the powder surface (as shown in Fig. 6d), which resulted in a round and smooth powder edge.

\subsection{Microstructural Evolution of Powder Compacts at Different HIPing Temperatures}

Figure 8 presents the microstructural evolution of powder compacts in the HIPing process at different temperatures. It can be seen that the HIPing temperature generally shows great influence on the microstructure, which is different from the results of the previous observation of raw powder samples (Fig. 6). This may be due to the simultaneous high pressure and temperature in a HIP run causing the powder to consolidate quickly, which results in powder deformation and liquid phase transfer. The prior particle boundary (PPB) can be observed and experienced the process of straight $\rightarrow$ irregular $\rightarrow$ straight, indicated by the blue line in Fig. 8f, g, h, i. Some micro-holes still exist in the powder compacts at $520{ }^{\circ} \mathrm{C}$ (Fig. $8 \mathrm{~g}$ ). As discussed above, most eutectics containing alloy elements in grain boundaries have dissolved during heating. However, the temperature rise in a HIP run should be very fast and the temperature will reach and exceed the eutectic reaction temperature in a short time. That is to say, there is not enough time for the complete dissolution of eutectics. When the temperature reached $502{ }^{\circ} \mathrm{C}$, the residual eutectics remelted and formed liquid pools. Finally, microholes were formed during solidification and the cooling of liquid phase due to liquid volume shrinkage and no supplement of excess liquid phase.

Through the EDS analysis (Fig. 8k, 1), it can be further seen that alloy elements such as $\mathrm{Cu}$ and $\mathrm{Mg}$ were concentrated at the junction of powder particles and the mole ratio of $\mathrm{Cu}-\mathrm{Al}$ was close to $1: 2$. Combined with the results of XRD and the phase transformation in the aluminum 


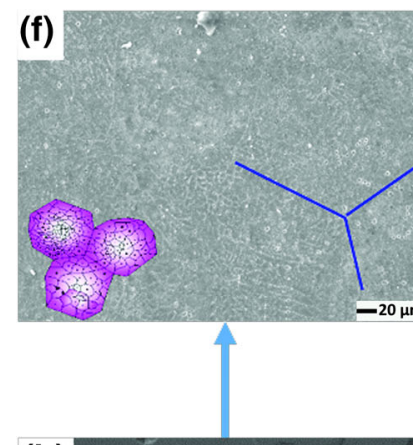

(b)
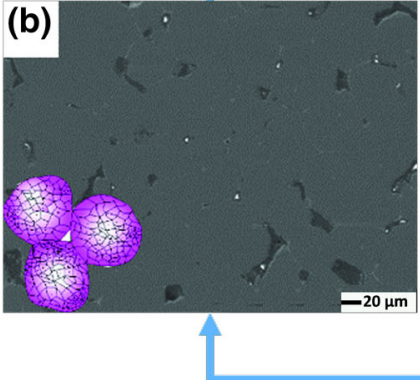
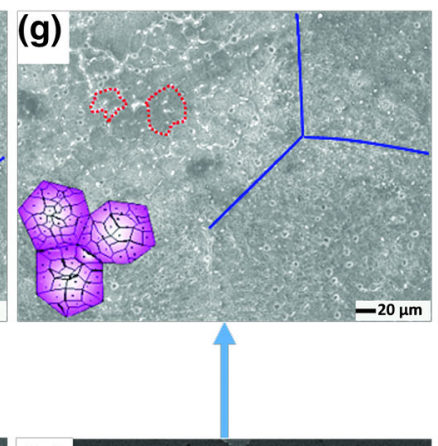

(c)
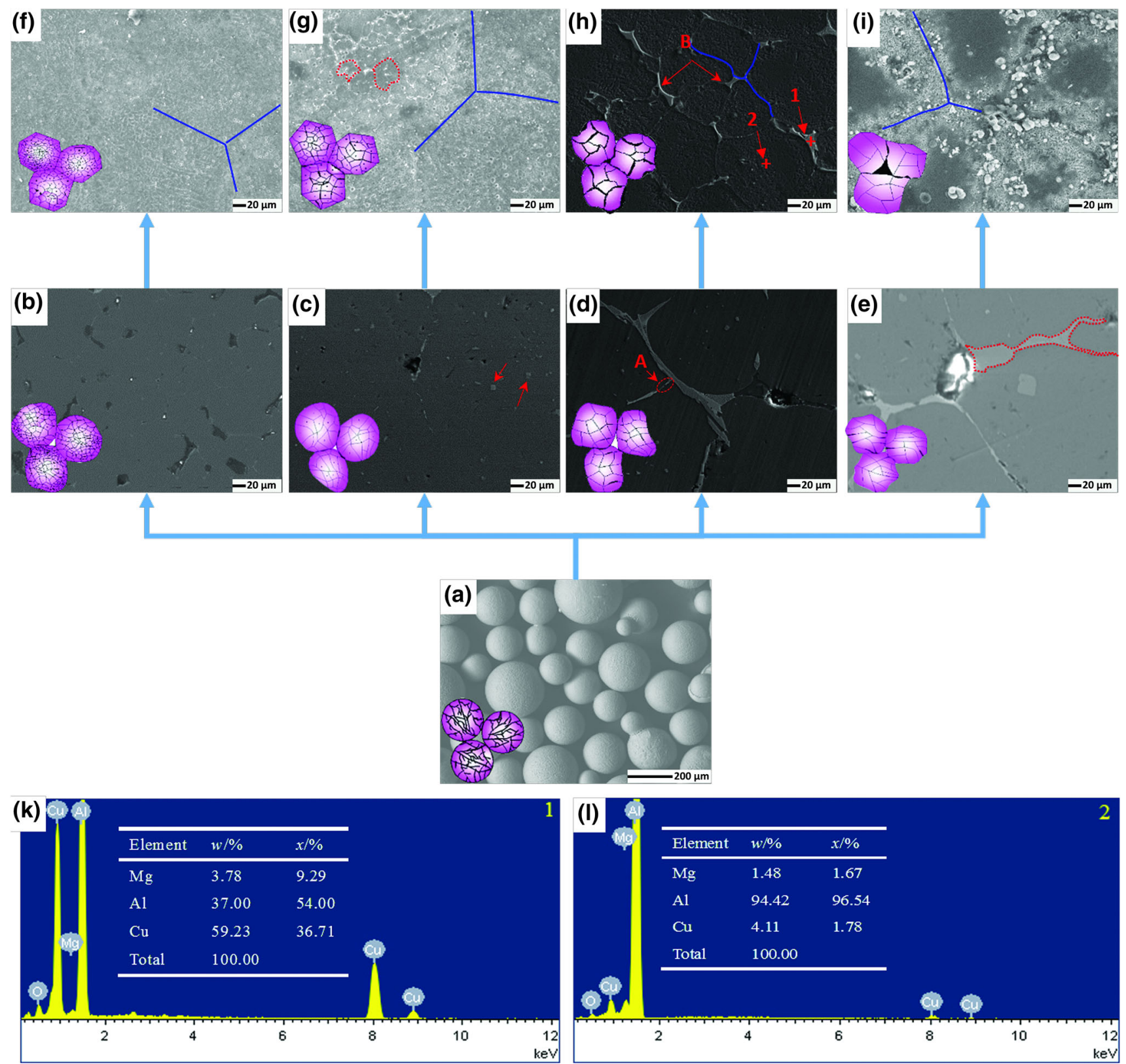

Fig. 8 Original powders a and microstructural evolution of powder compacts HIPed at different temperatures: f $490{ }^{\circ} \mathrm{C} ; \mathbf{g} 520{ }^{\circ} \mathrm{C} ; \mathbf{h} 580{ }^{\circ} \mathrm{C}$; i $600{ }^{\circ} \mathrm{C}$. The microstructure of powder compacts prepared by interrupted HIPing experiments after temperature preservation/pressure holding for 15 min at different temperatures: b $490{ }^{\circ} \mathrm{C}$; c $520{ }^{\circ} \mathrm{C}$; d $580{ }^{\circ} \mathrm{C}$; e $600{ }^{\circ} \mathrm{C}$. EDS spectra $\mathbf{k}$, l of the marked points in $\mathbf{~}$

alloy, it can be concluded that phase constituents located at the adjoiner of powder should contain $\theta\left(\mathrm{CuAl}_{2}\right), S\left(\mathrm{Al}_{2-}\right.$ $\mathrm{CuMg}$ ) and $\mathrm{MgAl}_{2} \mathrm{O}_{4}$. That is to say, the eutectic liquid phase generated inside the powder during heating was transferred to powder particle boundaries.

Powder rearrangement was in a form of point contact and a plenty of pores existed between the powder particles (Fig. 8a). With the increments of temperature and pressure, the amount of the pores decreased and direct contact of solid particles was found in Fig. 8b. Little liquid phase generated through ternary eutectic reaction at $520{ }^{\circ} \mathrm{C}$ dispersed in the powder compacts (as indicated by the red arrow in Fig. 8c). The liquid phase did not complete the transfer process under pressure because they existed independently in the form of the discrete points. Finally, a growing number of liquid phase points inside the powder formed the continuous grain boundaries (see the red dashed line in Fig. 8g).

When the temperature rose further to $580{ }^{\circ} \mathrm{C}$, the number of liquid phases was further increased because of the occurrence of the binary eutectic reaction and reached $20.23 \%$ (Table 2) and the powder particle boundaries 
presented as irregularly spherical (Fig. 8h). Isostatic pressure had a squeezing-out effect on the powder particles under high-temperature environments, which caused the partial liquid phase to be squeezed into the triple points of the powder particles. However, the liquid phase had not formed a continuous pathway from the powder surface to the inside (as shown in Fig. 6c) and the pathways that liquid phase transferred from the powder's inside to the surface were locked due to the squeezing and self-locking effect of the irregular solid phase, as indicated by arrow A in Fig. 8d. The partial liquid phase was trapped inside the powder and not squeezed out, which led to a uniform distribution of liquid phase between the powder surface and the inside, indicated by red arrow B in Fig. 8h. When the HIPing temperature was $600{ }^{\circ} \mathrm{C}$, the liquid content reached $38.14 \%$ (Table 2). Powder particles were easy to rotate because of the increasing liquid phase and the decreasing yield strength of the solid particles under high temperatures [29], which reduced the squeezing and selflocking effect of the irregular solid phase. In addition, the continuous liquid pathway had formed in the powder, as shown by the dotted line in Fig. 6d. All of these factors ensured that the liquid phase was squeezed out completely and accumulated at the triple points of the powder particles in a bell shape under external pressure, indicated by the red dotted lines in Fig. 8e. Finally, the liquid phase inside the powder was squeezed into the triple points of the powder particles entirely.

It is noteworthy that the microstructure of the powder compacts HIPed at $600{ }^{\circ} \mathrm{C}$ was different from the others, see Fig. 8i. There were many extrusive liquid spheres existing at the powder particle boundaries. It seemed that the solid phase in powder suffered easily from deformation due to the decrease in strength under high temperatures and the small powder particles located at the triple points were especially prone to deformation [30]. Besides, the amount of liquid under $600{ }^{\circ} \mathrm{C}$ is greater than those at other temperatures. Therefore, the liquid phase was squeezed out from the triple points by large powders and moved toward the side of small powders, finally forming the extrusive liquid spheres under the action of surface tension in the later cooling process, as indicated by the arrow in Fig. 9.

\subsection{Mechanical Property and Tensile Fracture Mode Analysis of Powder Compacts}

Figure 10 presents the tensile properties and relative density of the powder compacts HIPed at different temperatures. It can be seen that higher relative density and better mechanical properties were obtained when HIPing temperatures were 490 and $580{ }^{\circ} \mathrm{C}$. A comparison of our results with the literature is given in Table 3. From Table 3, it can be seen that the mechanical properties of the

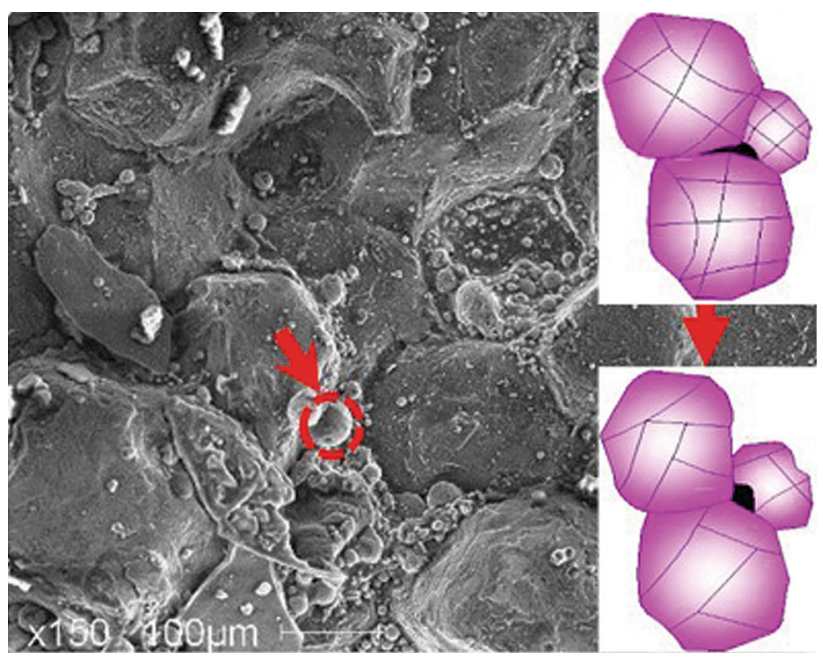

Fig. 9 Squeezing process of liquid phase and tensile fracture morphology of powder compact at HIPing temperature $600{ }^{\circ} \mathrm{C}$

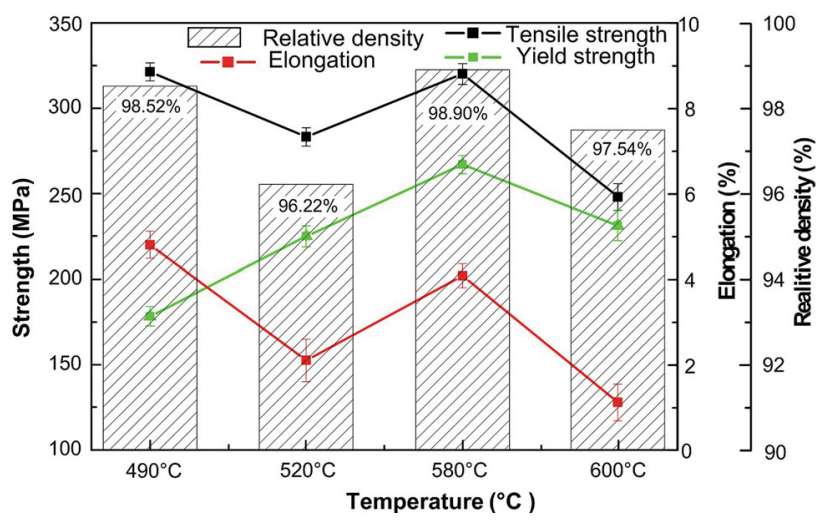

Fig. 10 Relative densities and mechanical properties of powder compacts

2A12 P/M aluminum alloy in the present research were lower than those of the $2 \mathrm{~A} 12$ aluminum alloy forgings, but higher than those of the similar grade alloys processed through powder metallurgy.

However, the powder compacts HIPed at $490{ }^{\circ} \mathrm{C}$ had lower yield strength and higher elongation than those at $580{ }^{\circ} \mathrm{C}$, which might be related to the lack of liquid phase generated in the powder. For the P/M aluminum alloy, a $15-20 \%$ liquid phase is needed to reach high relative density [34]; if there is too much liquid phase, the deformation or collapse of powder compacts would occur due to sedimentation of the liquid phase under gravity, which leads to a decrease in the mechanical properties $[35,36]$. According to the above-mentioned analysis, the content of liquid phase at $520{ }^{\circ} \mathrm{C}(0.26 \%)$ and $600{ }^{\circ} \mathrm{C}(38.14 \%)$ might not be a reasonable liquid phase fraction for the P/M aluminum alloy. As discussed above, there exist some microholes in the material at $520{ }^{\circ} \mathrm{C}$. Similarly, the accumulation of liquid phase would result in the formation of a crack 
Table 3 Comparison of the mechanical properties of 2A12 P/M aluminum alloy in the present study with those achieved from similar grade alloys processed through powder metallurgy and wrought route

\begin{tabular}{|c|c|c|c|c|c|}
\hline Alloy/processing condition & $\begin{array}{l}\text { Heat-treat } \\
\text { condition }\end{array}$ & $\begin{array}{l}\text { Ultimate tensile strength } \\
(\mathrm{MPa})\end{array}$ & $\begin{array}{l}\text { Yield strength } \\
(\mathrm{MPa})\end{array}$ & $\begin{array}{l}\text { Elongation } \\
(\%)\end{array}$ & Ref. \\
\hline $\begin{array}{l}\text { 2A12 P/M aluminum alloy (HIP at } \\
580^{\circ} \mathrm{C} \text { ) }\end{array}$ & - & 324 & 263 & 4 & $\begin{array}{l}\text { This } \\
\text { study }\end{array}$ \\
\hline $\begin{array}{l}2712 \mathrm{P} / \mathrm{M} \text { aluminum alloy (vacuum } \\
\text { sintered) }\end{array}$ & - & 178 & 138 & 6.2 & {$[14]$} \\
\hline $\begin{array}{l}2324 \mathrm{P} / \mathrm{M} \text { aluminum alloy (press and } \\
\text { sinter) }\end{array}$ & $\mathrm{T} 1$ & 248 & 186 & 1.87 & {$[11]$} \\
\hline 2014 P/M aluminum alloy (Ar sintered) & T6 & 178 & - & 3 & {$[31]$} \\
\hline ALUMIX123 (press and sinter) & $\mathrm{T} 4$ & 260 & 214 & 3 & {$[32]$} \\
\hline 2A12 aluminum alloy (wrought) & T6 & 390 & 295 & 10 & [33] \\
\hline
\end{tabular}

source in the later cooling process, owing to the volume shrinkage and no supplement of excess liquid phase when the HIPing temperature was $600{ }^{\circ} \mathrm{C}$. All of these factors would cause an undense defect in the powder compacts and have a negative influence on the mechanical properties of powder compacts. However, the distribution of liquid phase was more uniform at $580{ }^{\circ} \mathrm{C}$, compared with that at 520 and $600{ }^{\circ} \mathrm{C}$. Liu et al. [37] found that the liquid phase in the $\mathrm{P} / \mathrm{M}$ aluminum alloy played a role as a binder in the powder-forming process, which promoted the mechanical properties and relative density of the materials. This may be the reason for the better mechanical properties when the HIPing temperature is $580{ }^{\circ} \mathrm{C}$.

It can be further seen from Fig. 10 that the yield ratio becomes gradually larger as the temperature increases. However, the elongation has not always presented the downward trend. When the HIPing temperature was $580{ }^{\circ} \mathrm{C}$, the elongation significantly increased, which might imply that the amount and distribution of the liquid phase have an effect on the elongation, but the detailed relationship between them needs further research. Overall, the P/M aluminum alloy prepared by HIP had a low ductility and the average value of elongation was about $3.5 \%$.

In almost every case, an oxide skin (with a thickness of about 5-15 nm [38]) covers the outer surface of the aluminum alloy powder particles, which is thermally stable and prevents the sintering phenomenon between the particles [39]. This network of oxide films would be expected to be permanent features of the prior particle boundaries, effectively becoming the boundaries observed in the microstructure (indicated by the blue line in Fig. 8f, $\mathrm{g}, \mathrm{h}, \mathrm{i})$. The addition of some alloy elements, such as Sn and $\mathrm{Mg}$, can improve the bonding performance between the particles by de-oxidization [15, 40, 41]. Several previous studies [7, 42] indicated that the extremely stable aluminum oxide film was disrupted through the formation of liquid phase. Balog et al. [43] also stated that HIP could disrupt the native $\mathrm{Al}_{2} \mathrm{O}_{3}$ layer into separate nano-metric dispersoids. Although there were plenty of liquid phase generated in this study and the shape of powder particle also changed during the process of HIP, the oxide film seemed not to be penetrated by the liquid phase and still formed a continuous interpenetration skeleton. This was verified by the low elongation. In addition, the liquid phase is not expected to wet the alumina, even at high temperatures. Indeed, the contact angle is variously given as $\sim 103^{\circ}$ at $900{ }^{\circ} \mathrm{C}, \sim 160^{\circ}$ at $800{ }^{\circ} \mathrm{C}$ or $\sim 162^{\circ}$ at $950{ }^{\circ} \mathrm{C}$ [6].

In summary, besides the impact of distribution and transfer of the liquid phase, the existence of the oxide film on the surface of powder particles would result in interface formation, which was not only resistant to bonding, but might also be somewhat resistant to be wetted by the residual inter-dendritic liquid which would be forced out onto the surface of the oxide by the HIP pressure. All of these would have detrimental effects on the mechanical properties, especially elongation. However, the impingement of the oxide film at different HIPing temperatures has not been studied in detail, and the detailed mechanism needs further to be discussed and studied.

Figure 11 presents the vertical profile of fractures. It can be clearly seen from Fig. 11 that the structural components that appeared in the zone of material beneath the fracture surfaces were solid particles and a quenched liquid phase. Note that the liquid phase was in the form of a liquid film located at the powder boundaries (Fig. 11c) at $580{ }^{\circ} \mathrm{C}$ and in the form of liquid droplets on the fracture surface (marked by arrow D in Fig. 11d) at $600{ }^{\circ} \mathrm{C}$, which is consistent with previous observed results. The rare evidence of fractures within the powders (intra-granular fracture) was detected at $490{ }^{\circ} \mathrm{C}$, as indicated by arrow $\mathrm{A}$ in Fig. 11a, which implies that some areas in the material had a perfect inter-particle bonding and were strong enough to resist stress up to UTS when the HIPing temperature was $490{ }^{\circ} \mathrm{C}$. This may be the reason why the UTS is higher than those at other temperatures. However, the 

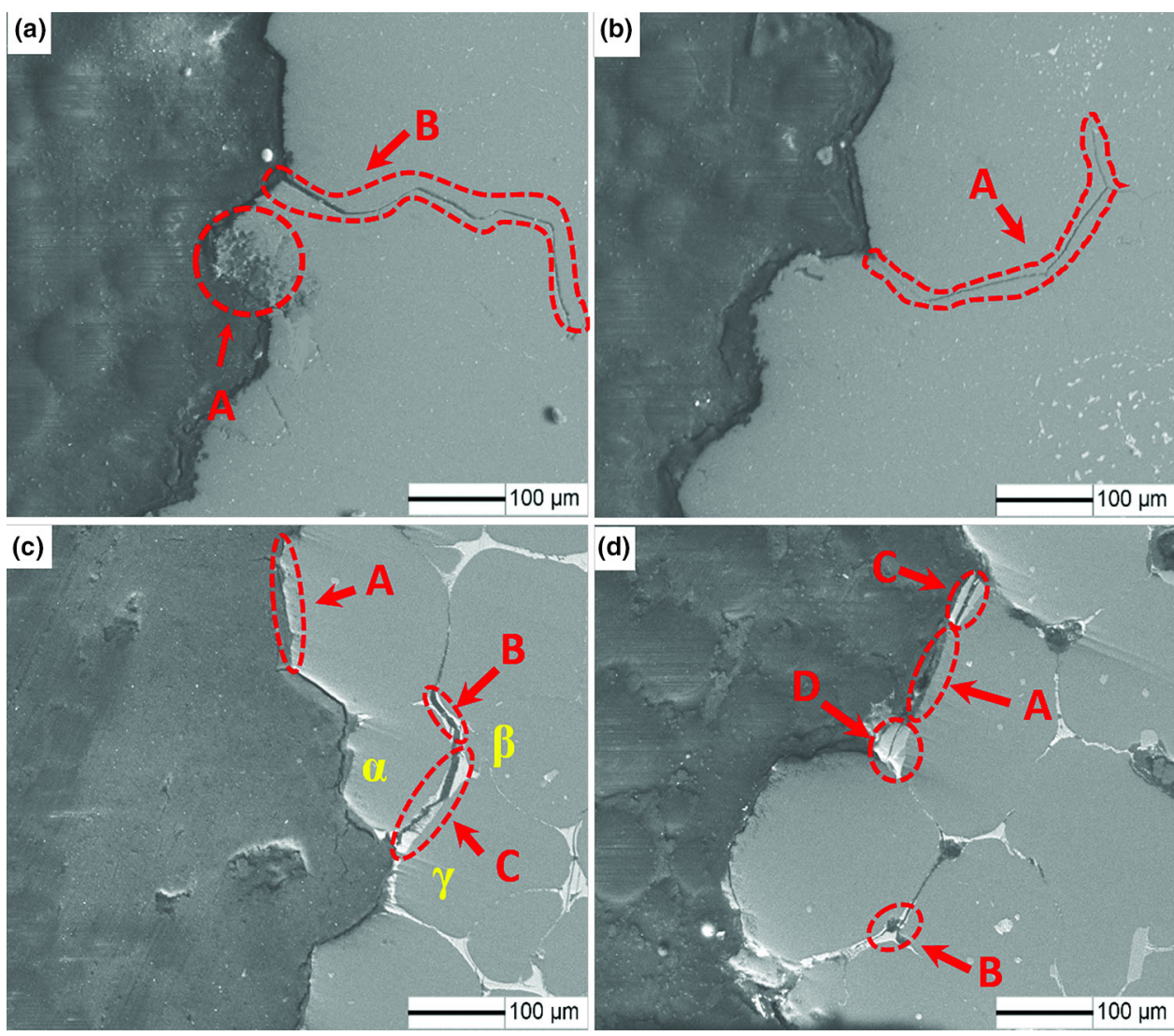

Fig. 11 SEM pictures of fracture profiles: a $490{ }^{\circ} \mathrm{C}$; b $520{ }^{\circ} \mathrm{C}$; c $580{ }^{\circ} \mathrm{C}$; d $600{ }^{\circ} \mathrm{C}$

absence of fractures within the powders might imply that the interface cohesion forces between the solid phase and liquid phase and/or the cohesion force of liquid film itself were lower than the force needed for de-cohesion within the powders when HIPing temperature was 490, 520, 580 and $600{ }^{\circ} \mathrm{C}$. Therefore, it can be concluded that powder particle boundary fractures mainly occurred in the powder compacts prepared by HIP, which also should be relative to the oxide film covering the surface of powder particles and the distribution of liquid phase discussed earlier.

According to Fig. 11, with the exception of the fracture within powders, three typical types of de-cohesion could be classified: (A) direct fracture along with the interface between the solid particles; (B) propagation of cracks through the liquid phase itself; and (C) direct detachment from the interface between the solid particles and the liquid phase. In other words, type (A) depends on the cohesion force between the solid particles, type (B) depends on the cohesion force of the liquid film, and type (C) depends on the interface cohesion force between the solid particles and the liquid phase. A schematic for de-cohesion type (A), (B) and (C) is shown in Fig. 12, in which the liquid film is indicated in blue. For powder compacts HIPed at 490 and $520{ }^{\circ} \mathrm{C}$, typical evidence of de-cohesion type (A), as well as local intra-granular fracture, is clearly shown by the arrow B in Fig. 11a and the arrow A in Fig. 11b. There was no or little liquid phase produced within the powders at the two temperatures, and the cohesion force between solid particles might be weak as a result of the absence of the bonding effect of the liquid phase and the existence of oxide film covering the surface of the powder particles. However, for the powder compacts HIPed at high temperatures $\left(580\right.$ and $600{ }^{\circ} \mathrm{C}$ ), the propagation of cracks along with the liquid film at the powder boundaries was clearly observed, as indicated by the arrow B in Fig. 11c and the arrow $\mathrm{C}$ in Fig. 11d, that is, de-cohesion type (B). Besides, arrow $\mathrm{C}$ in Fig. 11c clearly shows particular evidence of de-cohesion type $(\mathrm{C})$ : the rupture occurred at the triple point of the particles labeled $\alpha, \beta$ and $\gamma$, and it was followed by de-cohesion of the liquid film from the interface of $\alpha$ and $\gamma$. In other words, the powder particle $\alpha$ is nearly completely detached from the liquid film located at the particle boundary between $\alpha$ and $\gamma$ during the fracture. It should be noted that some fracture boundaries are straight and there is no residual liquid phase on them, as indicated by arrow A in Fig. 11c and arrow A in Fig. 11d, which also might be caused by de-cohesion type (C) and type (A). As discussed above, the cohesion force between the liquid phase and the oxide film covering the surface of the powder particles might be weak because of poor 

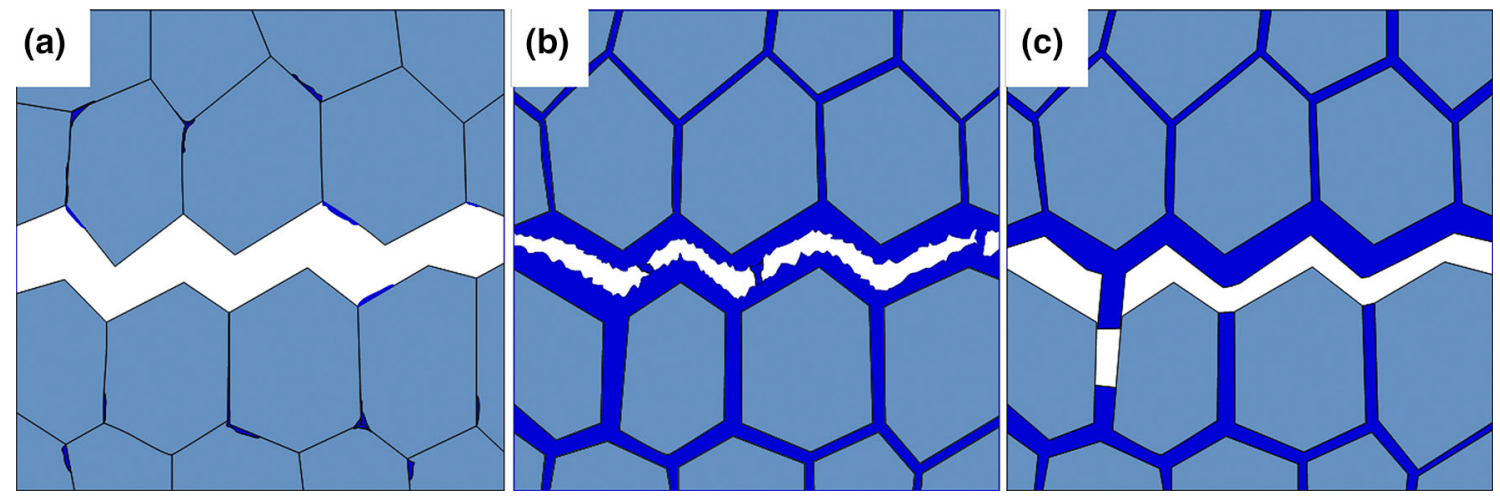

Fig. 12 Three typical types of de-cohesion: a direct fracture along with interface between solid particles; $\mathbf{b}$ propagation of cracks through the liquid phase itself; $\mathbf{c}$ direct detachment from the interface between solid phase and liquid phase

wettability, which might lead to direct detachment from the interface between the powder particles and the liquid phases, that is de-cohesion type (C). The distribution of the liquid phase was not absolutely uniform at some areas under pressure. Particularly at $600{ }^{\circ} \mathrm{C}$, almost all the liquid phase was squeezed into the triple points of the powder, which inevitably led to direct contact between the solid particles in some areas. Therefore, de-cohesion type (A) may arise in the course of tension. The two fracture modes mentioned above would cause the emergence of straight fracture boundaries.

Significantly, a large number of liquid phases accumulated at the triple points of the powder particles in the form of extrusive liquid spheres when HIPing temperature was $600{ }^{\circ} \mathrm{C}$, and a de-bonding might occurred between the liquid sphere and solid particles due to volume shrinkage of the liquid sphere in the cooling solidification process, which led to the formation of small crack sources. Then, the cracks tended to grow and spread along the particle boundaries due to stress concentration during the tensile test and led to final material failure. It is evident from arrow B in Fig. 11d that the formation and propagation of cracks were from the triple point of powders. Therefore, this may be another reason for the decrease in strength and elongation for the powder compacts HIPed at $600{ }^{\circ} \mathrm{C}$.

In summary, the main fracture mode was type (A) for the powder compacts HIPed at 490 and $520{ }^{\circ} \mathrm{C}$. However, when at high HIPing temperature $\left(580\right.$ and $\left.600{ }^{\circ} \mathrm{C}\right)$, the main fracture mode contained type (A), (B) and (C). It could be supposed that the characteristics of the liquid phase and nature of the interface cohesion between the coexisting phases (the solid phase and the liquid phase) have an effect on fracture behavior and the mechanical properties, besides the influence of oxide film. Nevertheless, the detailed mechanism is not clear. In addition, the influences of the inter-metallics on fracture behavior and the mechanical properties were not discussed in this study and some other features that were concerned in real service, such as thermal stability, fatigue property and hardness, were also not examined. The problems outlined above remain to be further investigated in the future.

\section{Conclusions}

1. The original dendrite structure of the powders changed into an equiaxed structure, and the liquid phase was generated in the powders through the eutectic reaction when HIPing temperature increased from 490 to $600{ }^{\circ} \mathrm{C}$. The continuous liquid pathway was gradually formed, and the edges of raw powder experienced the process of smooth $\rightarrow$ jagged $\rightarrow$ smooth with the increase in liquid phase content.

2. The prior particle boundary (PPB) in the powder compacts could be observed. The grains coarsened and the PPBs experienced the process of straight $\rightarrow$ irregular $\rightarrow$ straight with HIPing temperature increased from 490 to $600{ }^{\circ} \mathrm{C}$. The liquid phase was squeezed into the powder boundaries and the triple points of the powder particles under pressure when the HIPing temperature increased from 520 to $600{ }^{\circ} \mathrm{C}$. The liquid phase located at the triple points of the powder moved toward the side of small particles and finally formed extrusive liquid spheres at HIPing temperature of $600{ }^{\circ} \mathrm{C}$, which had a disadvantageous effect on the mechanical properties.

3. Higher relative density and better mechanical properties were obtained at HIPing temperatures of 490 and $580{ }^{\circ} \mathrm{C}$. However, the $\mathrm{P} / \mathrm{M}$ aluminum alloy prepared by HIP had a low ductility and the average value of elongation was about $3.5 \%$, which might be caused by the distribution characteristics of the liquid phase and existence of oxide film covering the outer surface of powder particles. Three typical de-cohesion characters were classified in the fractures: (A) direct fracture along with interface between solid particles; 
(B) propagation of cracks through the liquid phase itself; and (C) direct detachment from the interface between the solid phase and the liquid phase. For the alloy HIPed at 490 and $520^{\circ} \mathrm{C}$, the main fracture mode was (A), but the mixed fractures of (A), (B) and (C) were attained for the alloy HIPed at 580 and $600{ }^{\circ} \mathrm{C}$. In addition, the initiation and propagation of cracks caused by the influence of extrusive liquid phase spheres at the triple points of the powder decreased the mechanical properties of the P/M aluminum alloy.

Acknowledgments Thanks are given to Professor Li-hui Lang for useful discussion and help.

\section{References}

[1] M. Nakai, T. Eto, Mater. Sci. Eng. A 285, 62 (2000)

[2] W.S. Miller, L. Zhuang, J. Bottema, A.J. Wittebrood, P. De Smet, A. Haszler, Mater. Sci. Eng. A 280, 37 (2000)

[3] J. Capus, Met. Powder Rep. 70, 294 (2015)

[4] J. Capus, Met. Powder Rep. 68, 12 (2013)

[5] A. Heinz, A. Haszler, C. Keidel, Mater. Sci. Eng. A 280, 102 (2000)

[6] G.B. Schaffer, T.B. Sercombe, R.N. Lumley, Mater. Chem. Phys. 67, 85 (2001)

[7] J.M. Martín, F. Castro, J. Mater. Process. Technol. 144, 814 (2003)

[8] K.H. Min, S.P. Kang, B. Lee, J. Lee, Y.D. Kim, J. Alloys Compd. 419, 290 (2006)

[9] R.M. German, Sintering with a Liquid Phase, 9th edn. (Springer, Boston, 2014), pp. 247-303

[10] Z.Y. Liu, T.B. Sercombe, G.B. Schaffer, Metall. Mater. Trans. A 38, 1351 (2007)

[11] C.D. Boland, R.L. Hexemer, I.W. Donaldson, D.P. Bishop, Mater. Sci. Eng. A 559, 902 (2013)

[12] G.B. Schaffer, B.J. Hall, S.J. Bonner, S.H. Huo, T.B. Sercombe, Acta Mater. 54, 131 (2006)

[13] A. Gökçe, F. Findık, A.O. Kurt, Mater. Charact. 62, 730 (2011)

[14] C. Padmavathi, A. Upadhyaya, Trans. Indian Inst. Met. 64, 345 (2011)

[15] T.B. Sercombe, Mater. Sci. Eng. A 341, 163 (2003)
[16] C.L. Qiu, M.M. Attallah, X.H. Wu, P. Andrews, Mater. Sci. Eng. A 564, 176 (2013)

[17] J.T. Staley Jr., M. Tiryakioğlu, J. Campbell, Mater. Sci. Eng. A 465, 136 (2007)

[18] L. Ceschini, A. Morri, G. Sambogna, J. Mater. Process. Technol. 204, 231 (2008)

[19] G. Ran, J. Zhou, Q.G. Wang, J. Alloys Compd. 421, 80 (2006)

[20] M.A. Islam, Z.N. Farhat, Wear 271, 1594 (2011)

[21] L. Chang, W. Sun, Y. Cui, R. Yang, Mater. Sci. Eng. A 599, 186 (2014)

[22] Q. Wang, S.G. Li, H.J. Lv, G. Shi, S.Y. Huang, J.L. Shi, Titan. Ind. Prog. 5, 16 (2010)

[23] S. Yu, L.H. Lang, S. Yao, G. Wang, X.N. Huang, Y.Q. Xu, Chin. J. Nonferr. Metal. 10, 2745 (2015)

[24] P.B. Li, T.J. Chen, S.Q. Zhang, R.G. Guan, Metals 5, 547 (2015)

[25] Y. Zhang, S.K. Li, S.D. Chen, Powder Metall. Ind. 6, 13 (1998)

[26] Y.N. Dai, Binary Alloy Phase Diagrams, 4th edn. (Science Press, Beijing, 2009), pp. 56-59

[27] J. Mi, P.S. Grant, Acta Mater. 56, 1597 (2008)

[28] C.X. Gu, Dissertation, South China University of Technology, 2015 (in Chinese)

[29] R.M. German, A. Lal, J. Liu, Acta Mater. 47, 4615 (1999)

[30] Y. Xue, Dissertation, Beihang University, 2011 (in Chinese)

[31] A.K. Jha, Dissertation, Illinois Institute of Technology, 1983

[32] L. Dudas, W.A. Dean, Int. J. Powder Metall. 5, 113 (1969)

[33] B.Y. Huang, C.G. Li, L.K. Shi, G.Z. Qiu, T.Y. Zuo, China Materials Engineering Canon, 3rd edn. (Chemical Industry Press, Beijing, 2005), pp. 64-69

[34] G.C. Guo, Liquid-Sintering Powder Metallurgy Material, 2nd edn. (Chemical Industry Press, Beijing, 2003), pp. 23-29

[35] A. Mohammadzadeh, M. Azadbeh, H. Danninger, Powder Metall. 58, 123 (2015)

[36] M. Azadbeh, H. Danninger, C. Gierl-Mayer, Powder Metall. 56, $342(2013)$

[37] Y. Liu, X. Luo, Z. Li, J. Mater. Process. Technol. 214, 165 (2014)

[38] G.B. Schaffer, Mater. Forum 28, 65 (2004)

[39] J. Campbell, J. Mater. Sci. 51, 96 (2016)

[40] K. Kondoh, A. Kimura, R. Watanabe, Powder Metall. 44, 161 (2001)

[41] G.N. Grayson, G.B. Schaffer, J.R. Griffiths, Mater. Sci. Eng. A 454-455, 99 (2007)

[42] T. Pieczonka, T. Schubert, S. Baunack, B. Kieback, Mater. Sci. Eng. A 478, 251 (2008)

[43] M. Balog, C. Poletti, F. Simancik, M. Walcher, W. Rajner, J. Alloys Compd. 509, 235 (2011) 